\title{
Policy options for obesity in Europe: a comparison of public health specialists with other stakeholders
}

\author{
Laura I González-Zapata ${ }^{1,2,3, *}$ †, Carlos Alvarez-Dardet ${ }^{1,3}$, Rocio Ortiz-Moncada ${ }^{1}$, \\ Vicente Clemente ${ }^{1,3}$, Erik Millstone ${ }^{4}$, Michelle Holdsworth ${ }^{5}$, Katerina Sarri ${ }^{6}$, \\ Giulio Tarlao ${ }^{7}$, Zoltanne Horvath ${ }^{8}$, Tim Lobstein ${ }^{4}$ and Savvas Savva ${ }^{9}$ \\ ${ }^{1}$ Department of Public Health, Observatory of Public Policies and Health University of Alicante, Alicante, Spain: \\ ${ }^{2}$ Nutrition and Dietetics School, University of Antioquia, Medellín, Colombia: ${ }^{3}$ CIBER en Epidemiología y Salud \\ Pública (CIBERESP), University of Alicante, Alicante, Spain: ${ }^{4}$ Science and Technology Policy Research, University \\ of Sussex, Brighton, UK: ${ }^{5}$ Institut de Recherche pour le développement (IRD), Montpellier, France: ${ }^{6}$ Preventive \\ Medicine \& Nutrition Clinic, School of Medicine, University of Crete, Greece: ${ }^{7}$ Institute of International \\ Sociology, Gorizia, Italy: ${ }^{8}$ Department of Dietetics and Nutrition Sciences, Faculty of Health Sciences, \\ Semmelweis University, Budapest, Hungary: ${ }^{9}$ Research and Education Institute of Child Health, Strovolos, Cyprus
}

Submitted 19 October 2007: Accepted 3 April 2008: First published online 29 July 2008

\begin{abstract}
Objective: To explore policy options that public health specialists (PHS) consider appropriate for combating obesity in Europe, and compare their preferences with those of other stakeholders (non-PHS).

Design: Structured interviews using multicriteria mapping, a computer-based, decision-support tool.

Setting: Nine European countries.

Subjects: A total of 189 stakeholders. Twenty-seven interviewees were PHS and non-PHS included food, sports and health sectors.

Measurements: A four-step approach was taken, i.e. selecting options, defining criteria, scoring options quantitatively and weighting the criteria to provide overall rankings of options. Interviews were recorded and transcribed to yield qualitative data.

Results: The PHS concur with other stakeholders interviewed, as all emphasised the importance of educational initiatives in combating obesity, followed by policies to improve community sports facilities, introduce mandatory food labelling and controlling food and drink advertising. Further analyses revealed several significant differences. The non-PHS from the private sector ranked institutional reforms favourably; the PHS from non-Mediterranean countries supported the option of medicines to prevent obesity; and those PHS from Mediterranean countries endorsed the use of activity monitoring devices such as pedometers. As far as appraisal criteria were concerned, PHS considered efficacy and the economic impact on the public sector to be the most important.

Conclusion: There is clear consensus among PHS and other stakeholders concerning the need for a package of policy options, which suggests that European-wide implementation could be successful. However, it would be advisable to avoid more contentious policy options such as taxation until future changes in public opinion.
\end{abstract}

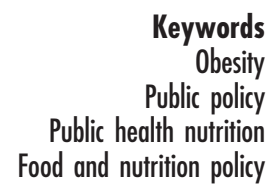

Obesity

Public policy

Food and nutrition policy
Obesity is a public health problem in Europe ${ }^{(1,2)}$. The epidemic nature of this problem means that the role of social and economic changes needs to be taken into account ${ }^{(3-6)}$. For example, the way that advertising aimed at children can manipulate their food preferences and

$\uparrow$ Correspondence address: Dpto. Enf. Comunitaria, Med Preventiva y Salud Pública, e Historia de la Ciencia - Área de Medicina Preventiva y Salud Pública, Campus de Sant Vicente del Raspeig. Ap. 99 E-03080, Spain. undermine parental guidance ${ }^{(7,8)}$. Corporations influence not only the policy-making process but also the way in which the public perceives the problem of obesity, encouraging consumers to see the obesity epidemic as the result of their own decisions, rather than as a consequence of social practices and environmental conditions promoted by the food and advertising industry ${ }^{(9)}$.

Although governments and health authorities are beginning to recognise the magnitude of the problem, discourse on this issue remains confused regarding its 
causes and even more so the actions that should be taken to improve the situation ${ }^{(9-12)}$. The social determinants of obesity are insufficiently understood and knowledge on the effectiveness of action taken, or to be taken, is incomplete $^{(6)}$. However, it is increasingly obvious that it is within the legal and regulatory framework of countries and regions that the socio-economic and cultural context is established; consequently, dietary intakes and physical activity are influenced by decisions made at a public policy and population level. Obesity can be influenced by regulatory policies and many governments acknowledge that prevention is a collective responsibility ${ }^{(7,12-15)}$.

Regulatory systems are by nature complex. Their functioning depends on a network of circumstances that converge with the interests of different stakeholders in a specific policy network, thus culminating in current practices. However, when regulatory instruments are used to control obesity, additional legislative problems sometimes arise or contradict legal cultures and practices, which are difficult for the public health specialists (or PHS) policymakers to anticipate ${ }^{(14)}$. Consequently, the question as to the role of State intervention in the issue of obesity as well as in other chronic illnesses remains to be clarified. It is also worth examining the extent to which the perspective of PHS is shared by other sets of stakeholders.

To address the challenge, many groups will need to be involved, including governments, public health advocates, the food industry and numerous other institutions. In order to deal with a complex public health problem such as obesity, it is necessary to understand their roles, the barriers that inhibit change and the factors that may facilitate it.

European policymakers also require more information on the policy options that stakeholders consider likely to be effective and acceptable ${ }^{(12,16)}$. Consulting with stakeholders is a necessary part of a successful policy-making process to assess the priorities, preferences and interests of key groups ${ }^{(17)}$. PHS have a pivotal role in the definition and implementation of policies to help resolve the issue of obesity in Europe. PHS are also likely to be particularly well-informed and concerned about obesity, and the present paper explores the extent to which their perceptions and judgements differ from or coincide with those of other stakeholders. Although the urgent need for public policy actions is undeniable, none of the actions taken until now has been coherent, effective or applicable for all EU countries. Therefore, it is crucial that for definition policies points of agreement and disagreement be identified among PHS, and compared with other stakeholders. There is a longstanding belief that attitudes between PHS and those in the food industry are polarised with regard to appropriate solutions for the obesity epidemic, and the present paper examined whether this polarity actually exists.

The present paper explores the policy options that PHS consider appropriate for combating obesity in Europe, comparing their rankings and judgements with those of other non-PHS (NPHS) stakeholders. Further comparisons will be made between variations in public and private sectors, Mediterranean and non-Mediterranean countries, and differences in the criteria selected by stakeholders themselves.

\section{Methods}

Multicriteria mapping $(\mathrm{MCM})^{(18,19)}$ is the novel decision analysis technique used in the present study to provide an integrative, comparative analysis of the different viewpoints of key stakeholders and PHS, regarding a broad range of policy options concerning obesity.

The MCM procedure has been described in detail elsewhere ${ }^{(19,20)}$. Quantitative and qualitative data were gathered from a large number of stakeholders to ensure that a comprehensive range of views was mapped. The nine national teams contributing to the Policy Options for Responding to the Growing Challenge of Obesity Research (PorGrow) project selected twenty-one stakeholder categories to be interviewed in each of the countries (Cyprus, Finland, France, Greece, Hungary, Italy, Poland, Spain and the UK), representing actors and institutions that may play an important role in policy making, either directly or through networks of influence $^{(21)}$. It was possible to cluster those categories of participants into affinity groups of stakeholders sharing common commercial, corporate or professional interests. These six groups were called 'Perspectives', and they were characterised as shown in Table 1.

The countries were chosen to encompass Europe's contrasting economies, gastronomies, geographies and cultures. The stakeholders were chosen to encompass those groups likely to be essential in, or important to, an effective policy network.

To select the individual interviewees to represent the twenty-one stakeholders' categories, national teams used both an exhaustive web search (using as key words the translation into local languages of the stakeholders categories previously agreed) and a snowball approach using information gathered from key informants and the identified stakeholders. The rule was to select stakeholders of the highest level nationally, who were involved in corporate or public policy making and could be a spokesperson for their stakeholder category. The project coordinator (E.M.) ensured that there was sufficient comparability of stakeholder roles between countries by discussing with the participating teams issues around cross-country comparisons of the national roles of the identified stakeholders.

Once the candidates for interview were identified, they were contacted by telephone and sent an invitation letter, along with a leaflet in local languages with information on the project. When the selected stakeholders agreed to 
Table 1 Interviewees grouped into perspectives for analytical purposes

\begin{tabular}{ll}
\hline Perspectives & \multicolumn{1}{c}{ Category } \\
\hline A. Public interest non-governmental organisations & 7. Representatives of consumer groups \\
& 19. Public health non-governmental representatives \\
& 20. Public interest sport and fitness non-governmental organisation \\
B. Food chain large industrial and commercial organisations & 21. Representatives of trades unions \\
& 1. Farming industry representative \\
& 2. Food processing company representatives \\
& 3. Representatives of large commercial catering chains \\
C. Small food and fitness commercial organisations & 4. Representatives of large food retailers \\
& 5. Representatives of small 'health' food retailers \\
D. Large non-food industrial and commercial organisations & 13. Representatives of commercial sport or fitness providers \\
& 12. Representatives of life insurance industry \\
E. Policy makers & 17. Representatives of advertising industry \\
F. Public providers & 18. Representatives of the pharmaceutical industry \\
& 8. Senior official government policy makers in health ministry \\
G. Public health specialists & 9. Senior official government policy makers in finance ministry \\
& 6. Representatives of public sector caterers (e.g. school meal providers) \\
& 11. Town and transport planners \\
& 14. Representatives of school teachers
\end{tabular}

participate, a second package with information on MCM methodology and an example of a previous mapping exercise on energy options was sent by post. They were contacted again by phone to address any remaining questions, given further information when required, and to arrange a date and place to conduct the $2-3 \mathrm{~h}$ interview in an appropriate way, without interruption. This process is known as 'scoping,(19). The interviews were conducted following a common procedure, which included recording and the use of a special software package specially developed for the project and strictly following the procedures described in the interview manual (http:// www.sussex.ac.uk/spru/documents/02_mcm_interview_ manual.pdf).

The MCM interview consists of four steps. Firstly, participants selected and defined a set of policy options that they will evaluate. In advance of the formal start of the project, an attempt was made to identify as wide a range as possible of the policy options that were under consideration by public policy makers and public health policy analysis for responding to the increasing incidence of obesity. The scope of that examination included international organisations such as the WHO and the European Commission, and the governments of European Union (EU) Member States, as well as national and EU non-governmental organisations (NGO) representing industrial, commercial, consumer and public health organisations.

In advance of the project's initial launch meeting in September 2004, interpartner exchanges had produced a set of some twenty-eight policy options from which core and discretionary options could be chosen. All the partners in the nine participating countries were asked to indicate which of those options could sensibly be considered as relevant to their national contexts. The resulting set of options was then divided into two subsets: namely those that were candidates for the role of 'core options' and those that were candidates for the role of 'discretionary options', and these were tabled by the principal investigator (E.M.) at the first project meeting.

Core options were to be appraised by all interviewees in all countries, while they could appraise as many or as few discretionary options as they wished. A debate resulted in an agreed list of seven core options and thirteen discretionary options. Interviewees could also introduce and define any 'additional' options they saw fit. The twenty 'predefined options' (core + discretionary) are presented in summary form in Table 2.

The software package generated graphic representation of the relative performance of each policy option. Examples are provided in Figs 1-6, in which the core options - appraised by all participants - are represented by the top seven bars, and the discretionary options, which were selected by some but not all interviewees, are represented by the lower set of bars, ranked from the most favoured at the top to the least favoured at the bottom. The horizontal scale is normalised and ordinal rather than cardinal. A distinctive pattern is used to differentiate members of the six options clusters.

Secondly, a set of evaluative criteria was then introduced by each interviewee reflecting their particular viewpoints. The 'criteria' were the various factors that the interviewee considered when they scored and compared the pros and cons of different options. The criteria addressed the issues influenced their assessment of the performance of the options, but the criteria had to be applicable to all the options.

Thirdly, options were evaluated according to each criterion and numerical scores were given by the interviewees: the higher the score, the more optimistic the 
Table 2 Core and discretionary options grouped by clusters

\begin{tabular}{|c|c|c|}
\hline Cluster & Core options & Discretionary options \\
\hline $\begin{array}{l}\text { Cluster } 1 . \text { Exercise and physical } \\
\text { activity oriented }\end{array}$ & $\begin{array}{l}\text { 1. Change planning and transport } \\
\text { policies } \\
\text { 2. Improve community sports facilities }\end{array}$ & $\begin{array}{l}\text { 20. Increase the use of physical activity } \\
\text { monitoring devices }\end{array}$ \\
\hline $\begin{array}{l}\text { Cluster } 2 . \text { Modifying the supply of, } \\
\text { and demand for, foodstuffs }\end{array}$ & $\begin{array}{l}\text { 4. Control sales of foods in public } \\
\text { institutions } \\
\text { 6. Provide subsidies on healthy foods } \\
\text { 7. Impose taxes on obesity-promoting } \\
\text { foods }\end{array}$ & $\begin{array}{l}\text { 11. Control the composition of processed food } \\
\text { products } \\
\text { 12. Provide incentives to improve food composition } \\
\text { 14. Provide incentives to caterers to provide } \\
\text { healthier menus }\end{array}$ \\
\hline $\begin{array}{l}\text { Cluster 3. Information-related } \\
\text { initiatives } \\
\text { Cluster } 4 \text {. Educational and } \\
\text { research initiatives }\end{array}$ & $\begin{array}{l}\text { 3. Controls on food and drink advertising } \\
\text { 5. Require mandatory nutrition labelling }\end{array}$ & $\begin{array}{l}\text { 19. Control the use of marketing terms ('diet', } \\
\text { 'light,' etc.) } \\
\text { 8. Improve training for health professionals in } \\
\text { obesity care } \\
\text { 10. Improve health education for the general } \\
\text { public } \\
\text { 13. Increase research into obesity prevention } \\
\text { and treatment } \\
\text { 15. Include food and health in the school } \\
\text { curriculum }\end{array}$ \\
\hline $\begin{array}{l}\text { Cluster } 5 . \text { Technological } \\
\text { innovation }\end{array}$ & & $\begin{array}{l}\text { 16. Increase the use of medication to control } \\
\text { bodyweight } \\
\text { 17. Increase the use of synthetic fats and artificial } \\
\text { sweeteners }\end{array}$ \\
\hline Cluster 6. Institutional reforms & & $\begin{array}{l}\text { 9. Reform the Common Agricultural Policy to } \\
\text { support nutritional targets } \\
\text { 18. Create a new governmental body to coordinate } \\
\text { policies on obesity }\end{array}$ \\
\hline
\end{tabular}

performance of the appraised option. Since option performance would often depend on decisions that had not yet been taken, interviewees were asked to indicate their judgements of the performance of the options by awarding both an optimistic and a pessimistic score to each option; the gap between those scores provided an indicator of uncertainty. Fourthly, a quantitative weighting was assigned to each criterion, to reflect their relative importance according to the interviewee. Using a simple formula, the scores under each criterion were multiplied by the criteria weightings to produce an overall pessimistic and optimistic relative ranking for each option.

To facilitate data analysis, a separate specialist software package called MCM Analyst was developed by the University of Sussex, as part of the PorGrow project. This includes a relational database containing all data relating to all participants, interlinked with textual reports for representing relevant sections of the qualitative data in graphics and narrative forms. It was possible to analyse policy options individually or combined into the clusters. For comparability, all national teams agreed to initiate analysis of the options with a common set of clusters (see Table 2).

In this discussion, the 189 stakeholders from nine countries are grouped into two sets: twenty-seven PHS interviewees and 162 NPHS interviewees. Furthermore, and in order to take into account the possibility that certain appraisals may be influenced by stakeholders' 'vested' interests, NPHS participants were divided into two groups, based on their status as public sector (PuS): eighty-one interviewees from categories 6, 7, 8, 9, 11, 14, 19, 20 and 21, or the private sector ( $\operatorname{PrS})$ : eighty-one interviewees from categories 1, 2, 3, 4, 5, 12, 13, 17 and 18 (categories are listed in Table 1).

The PHS were also compared with respect to their geographical locations: Mediterranean (PHSM), twelve interviewees from Cyprus, Greece, Italy and Spain; and non-Mediterranean (PHSNM), fifteen interviewees from Finland, France, Hungary, Poland and the UK.

\section{Results}

The interviews were conducted between November 2004 and May 2005. Twenty-one stakeholder categories were interviewed in each country (with the exception of Greece, where category 6 was subsumed within category 3). Not all stakeholders appraised all of the options; compliance in the appraisal of the seven core options was very good, with all countries (except Greece) obtaining appraisals of all the core options by all stakeholders. Engagement with the discretionary options varied between countries, the options most often chosen for appraisal were general health education and school food and health education, which were appraised by $68 \%$ and $73 \%$ of all stakeholders, respectively. Options least often chosen for appraisal were medication for weight control, greater use of fat and sugar substitutes and physical activity monitoring devices, which were appraised by less than one-fifth of all participants. 
(a)

$$
\begin{array}{r}
\text { 2. Improve communal sports facilities (C) } \\
\text { 5. Mandatory nutritional information labelling (C) } \\
\text { 3. Controls on food and drink advertising (C) } \\
\text { 4. Controlling sales of foods in public institutions (C) } \\
\text { 6. Subsidies on healthy foods (C) } \\
\text { 1. Change planning and transport policies (C) }
\end{array}
$$

(RULED OUT BY SOME \#1) 7. Taxes on obesity-promoting foods (C)

15. Food and health education (D)

10. Improved health education (D)

8. Improve training for health professionals (D)

14. Provide healthier catering menus (D)

18. New government body (D)

13. More obesity research (D)

16. Medication for weight control (D)

11. Controls on food composition (D)

20. Physical activity monitoring devices (D)

12. Incentives to improve food composition (D)

19. Control of marketing terms (D)

9. Common Agricultural Policy reform (D)

17. Substitutes for fat and sugar (D)

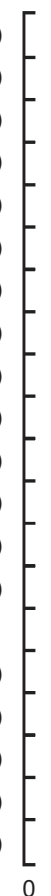

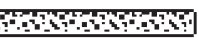

Dod00000

30000000

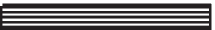

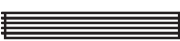

EDEDEDEDEDA
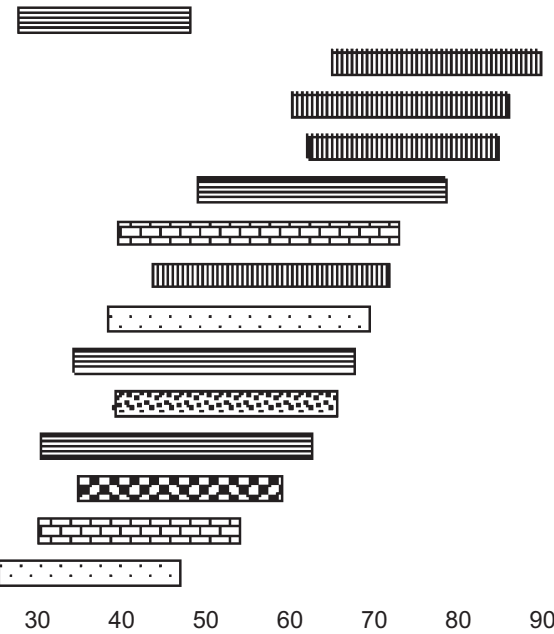

(b)

(RULED OUT BY SOME \#2) 5. Mandatory nutritional information labelling (C)

2. Improve communal sports facilities (C)
ndatory nutritional information labelling (C)

(RULED OUT BY SOME \#4) 3. Controls on food and drink advertising (C)

(RULED OUT BY SOME \#1) 4. Controlling sales of foods in public institutions (C)

1. Change planning and transport policies $(C)$

(RULED OUT BY SOME \#4) 6. Subsidies on healthy foods (C) (RULED OUT BY SOME \#6) 7. Taxes on obesity-promoting foods (C) 15. Food and health education (D)

10. Improved health education (D)

8. Improve training for health professionals (D)

13. More obesity research (D)

14. Provide healthier catering menus (D)

(RULED OUT BY SOME \#3) 11. Controls on food composition (D)

18. New government body (D)

(RULED OUT BY SOME \#1) 19. Control of marketing terms (D)

(RULED OUT BY SOME \#1) 9. Common Agricultural Policy reform (D)

(RULED OUT BY SOME \#2) 12. Incentives to improve food composition (D) 20. Physical activity monitoring devices (D)

(RULED OUT BY SOME \#1) 16. Medication for weight control (D) 17. Substitutes for fat and sugar (D)
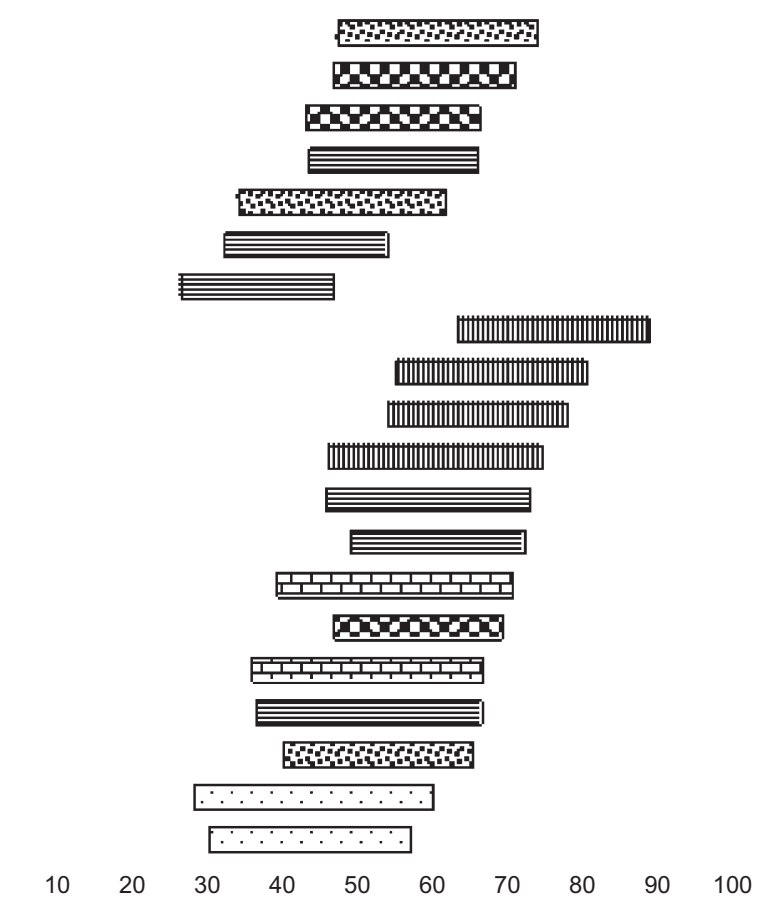

Fig. 1 Rank means for (a) public health specialists' and (b) non-public health specialists' perspectives (欰, education; 7 : physical activity; 臣, institutional reform; $\mathbf{X}$, information; 韭, food supply \& demand; $\because$, technology)

The PHS evaluations of the group of both core and discretionary policy options were surprisingly similar to the NPHS. Both highlighted educational initiatives as the most important options; specifically, to include food and health in the school curriculum, to improve health education in the population in general and to improve the training of health professionals in the overall mapping of public policy options.

For example the Greek PHS said:

All strategies should aim at primary prevention and not secondary prevention. Our aim should be to 

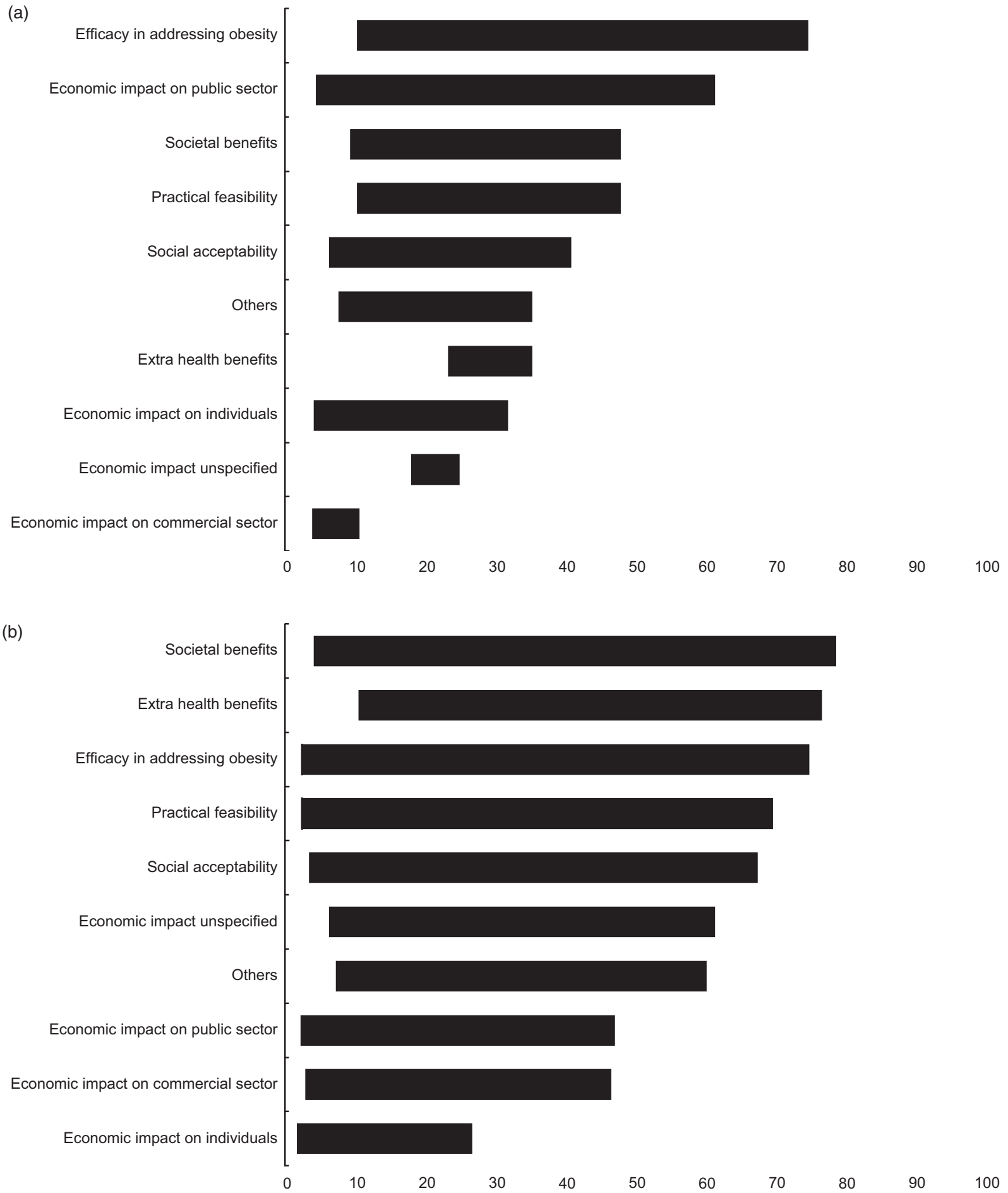

Fig. 2 Weight extrema for (a) public health specialists' and (b) non-public health specialists' perspectives

inform and educate citizens before they develop a health problem or they have adopted habits that are difficult to change... Therefore, it is a lot better to implement a preventive program in kindergarden and primary school where children have not formed their habits yet instead of implementing it at high school. Another observation is that all strategies for tackling obesity should be integrated in a more general framework for increasing awareness regarding Public Health issues. In this way, the 'antiobesity' strategies will not be easily forgotten.

The similarities indicated in Fig. 1 reflect, in part, the fact that the ends of the bars indicate the averages 
(a)

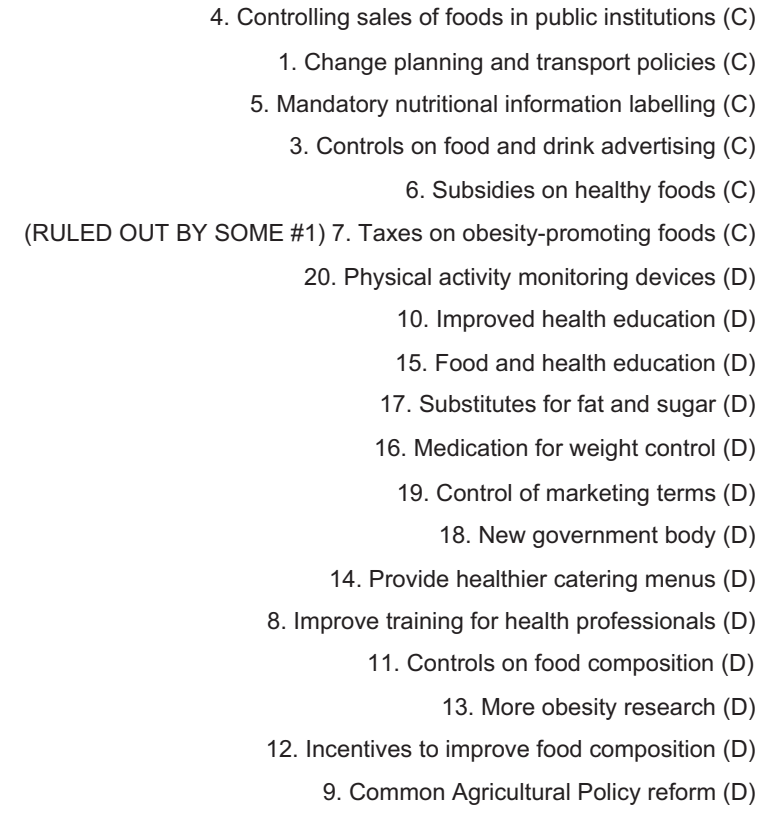

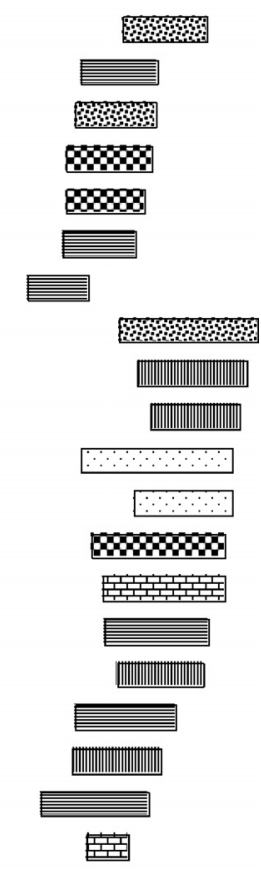

(b)

\footnotetext{
2. Improve communal sports facilities (C) 1. Change planning and transport policies (C)
}

(RULED OUT BY SOME \#2) 5. Mandatory nutritional information labelling (C)

(RULED OUT BY SOME \#4) 3. Controls on food and drink advertising (C)

(RULED OUT BY SOME \#1) 4. Controlling sales of foods in public institutions (C)

(RULED OUT BY SOME \#4) 6. Subsidies on healthy foods (C)

(RULED OUT BY SOME \#6) 7. Taxes on obesity-promoting foods (C)

$$
\begin{aligned}
& \text { 15. Food and health education (D) } \\
& \text { 10. Improved health education (D) } \\
& \text { 13. More obesity research (D) }
\end{aligned}
$$

(RULED OUT BY SOME \#3) 11. Controls on food composition (D)

8. Improve training for health professionals (D)

14. Provide healthier catering menus (D)

(RULED OUT BY SOME \#2) 12. Incentives to improve food composition (D)

(RULED OUT BY SOME \#1) 16. Medication for weight control (D)

18. New government body (D)

(RULED OUT BY SOME \#1) 9. Common Agricultural Policy reform (D)

20. Physical activity monitoring devices (D)

(RULED OUT BY SOME \#1) 19. Control of marketing terms (D)

17. Substitutes for fat and sugar (D)

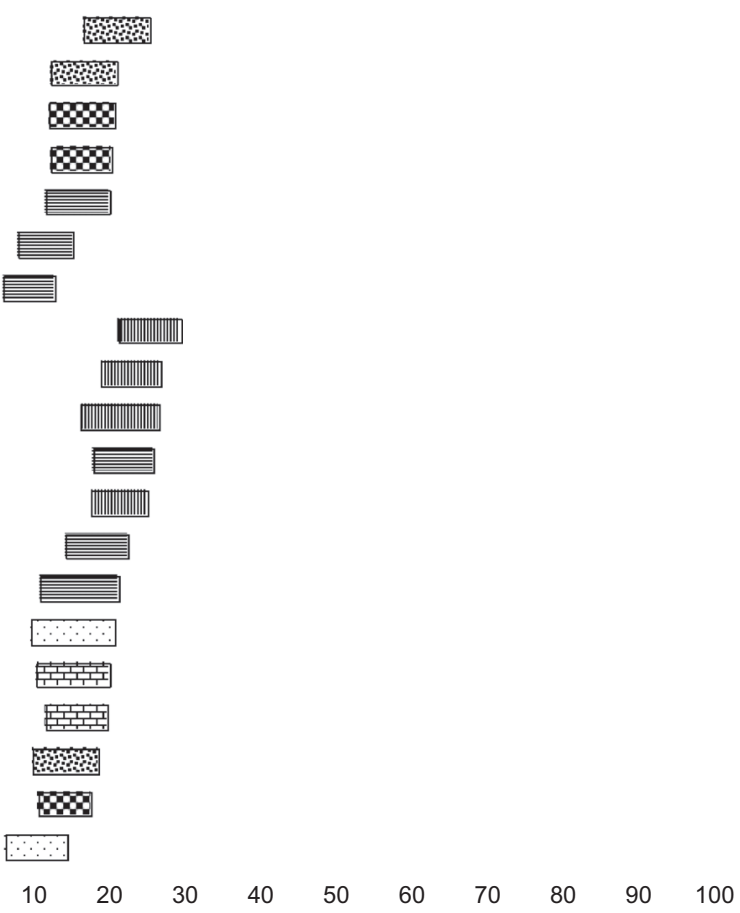

Fig. 3 Summed scores for (a) public health specialists' and (b) non-public health specialists' perspectives on efficacy in addressing

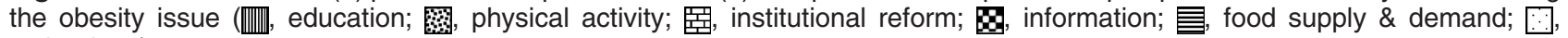
technology)

of the interviewees' optimistic and pessimistic judgements, not the extremes of those judgements. In practice, there was far greater variability in the judgements of the NPHS than among the PHS interviewees, which is not shown in Fig. 1, but can be seen from more detailed reports $^{(21)}$. The apparent similarities between the evaluations of the PHS and NPHS suggest however that the analyses and views of PHS have diffused into the wider national cultures, and on average are distinctly influential. 


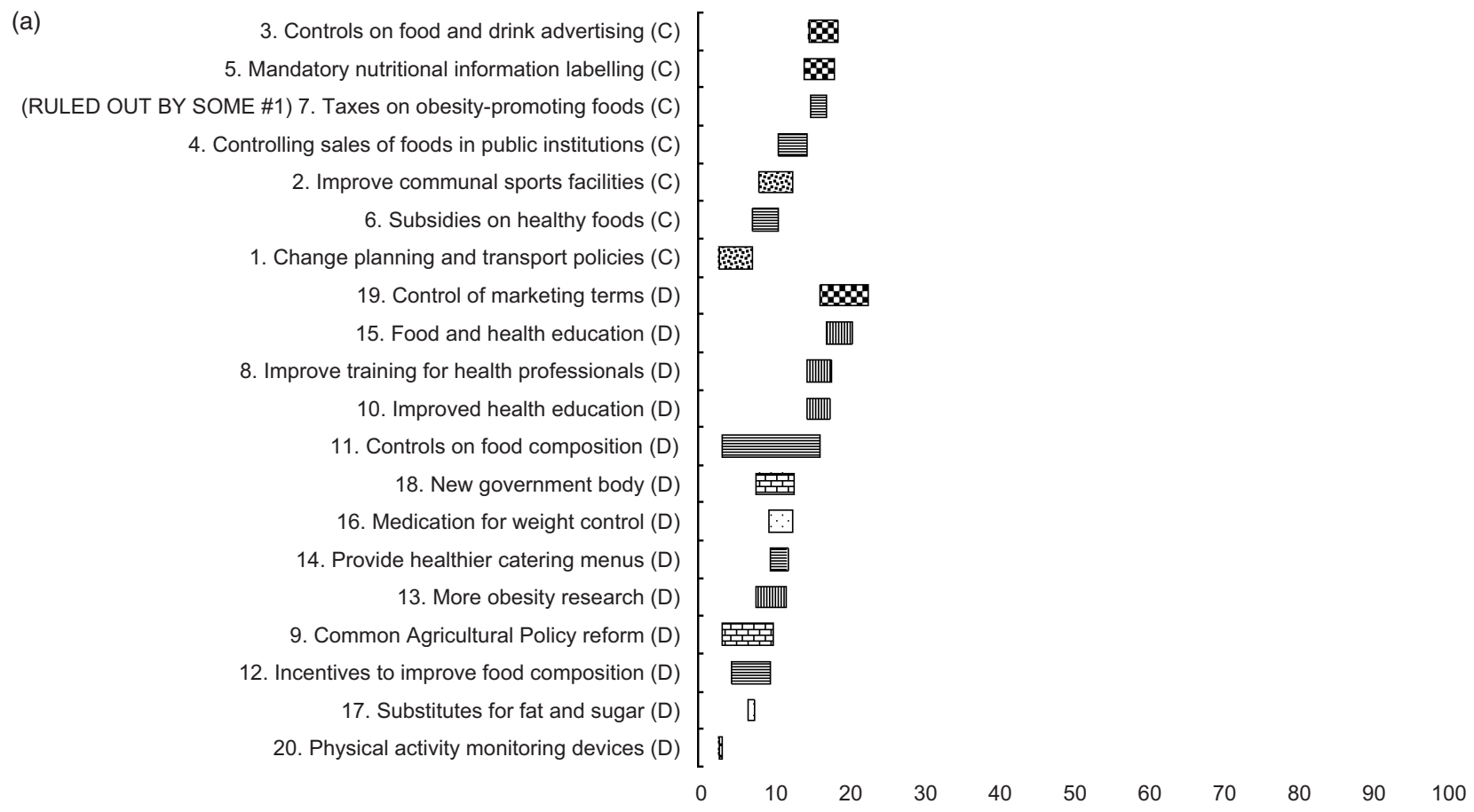

(b)

(RULED OUT BY SOME \#1) 4. Controlling sales of foods in public institutions (C)

(RULED OUT BY SOME \#2) 5. Mandatory nutritional information labelling (C) (RULED OUT BY SOME \#4) 3. Controls on food and drink advertising (C) (RULED OUT BY SOME \#6) 7. Taxes on obesity-promoting foods (C)

2. Improve communal sports facilities (C) (RULED OUT BY SOME \#4) 6. Subsidies on healthy foods (C) 1. Change planning and transport policies $(C)$ 15. Food and health education (D) 13. More obesity research (D) 18. New government body (D) (RULED OUT BY SOME \#3) 11. Controls on food composition (D) 10. Improved health education (D) (RULED OUT BY SOME \#1) 19. Control of marketing terms (D) 8. Improve training for health professionals (D) 20. Physical activity monitoring devices (D) (RULED OUT BY SOME \#1) 9. Common Agricultural Policy reform (D) (RULED OUT BY SOME \#2) 12. Incentives to improve food composition (D) (RULED OUT BY SOME \#1) 16. Medication for weight control (D) 14. Provide healthier catering menus (D) 17. Substitutes for fat and sugar (D)

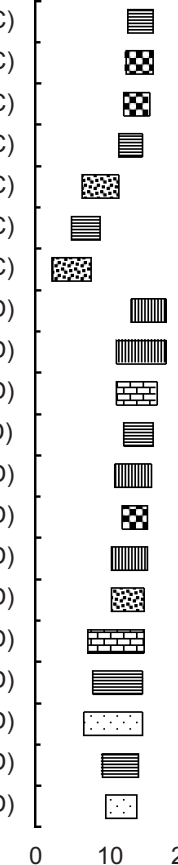

Fig. 4 Summed scores for (a) public health specialists' and (b) non-public health specialists' perspectives on economic

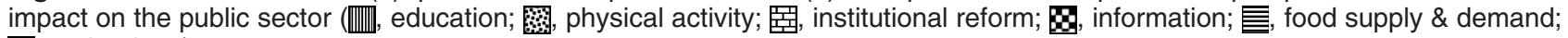
$\therefore$, technology)

The comparative quantitative analysis of PHS $v$. NPHS, shown in Fig. 1, reflects some differences in their evaluations. PHS rated the policy option of subsidies on healthy foods and the use of medication to control body weight more highly than NPHS. The least favoured options for both PHS and NPHS groups were technological innovations and the application of taxes on obesogenic products. Enthusiasm for pharmaceutical interventions 
(a) 2. Improve communal sports facilities $(C)$

(RULED OUT BY SOME \#1) 4. Controlling sales of foods in public institutions (C) (RULED OUT BY SOME \#2) 3. Controls on food and drink advertising (C)

1. Change planning and transport policies (C) 6. Subsidies on healthy foods (C) (RULED OUT BY SOME \#1) 7. Taxes on obesity-promoting foods (C) 15. Food and health education (D) 10. Improved health education (D) 8. Improve training for health professionals (D) 13. More obesity research (D) 11. Controls on food composition (D) 19. Control of marketing terms (D) 18. New government body (D)

14. Provide healthier catering menus (D) 12. Incentives to improve food composition (D)

9. Common Agricultural Policy reform (D) 20. Physical activity monitoring devices (D) 17. Substitutes for fat and sugar (D) 16. Medication for weight control (D)

(b)

(RULED OUT BY SOME \#2) 5. Mandator

(RULED OUT BY SOME \#4) 3. Controls on food and drink advertising (C) (RULED OUT BY SOME \#1) 4. Controlling sales of foods in public institutions (C)

1. Change planning and transport policies $(C)$

(RULED OUT BY SOME \#4) 6. Subsidies on healthy foods (C) (RULED OUT BY SOME \#6) 7. Taxes on obesity-promoting foods (C) 15. Food and health education (D) 10. Improved health education (D) 8. Improve training for health professionals (D) 14. Provide healthier catering menus (D) 13. More obesity research (D) (RULED OUT BY SOME \#1) 9. Common Agricultural Policy reform (D) 18. New government body (D)

(RULED OUT BY SOME \#3) 11. Controls on food composition (D) 20. Physical activity monitoring devices (D) (RULED OUT BY SOME \#1) 16. Medication for weight control (D) (RULED OUT BY SOME \#1) 19. Control of marketing terms (D) (RULED OUT BY SOME \#2) 12. Incentives to improve food composition (D) 17. Substitutes for fat and sugar (D)

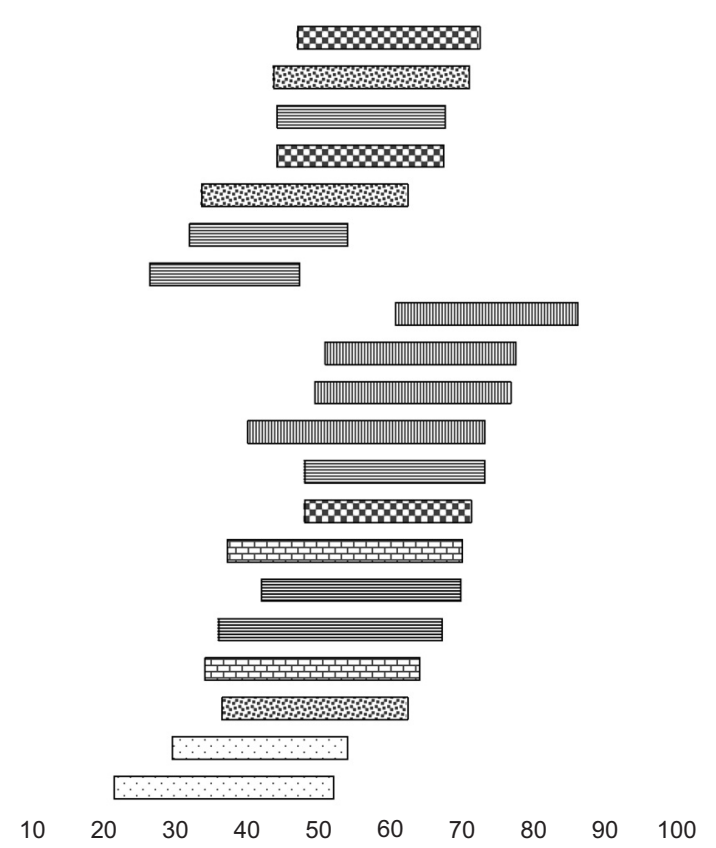

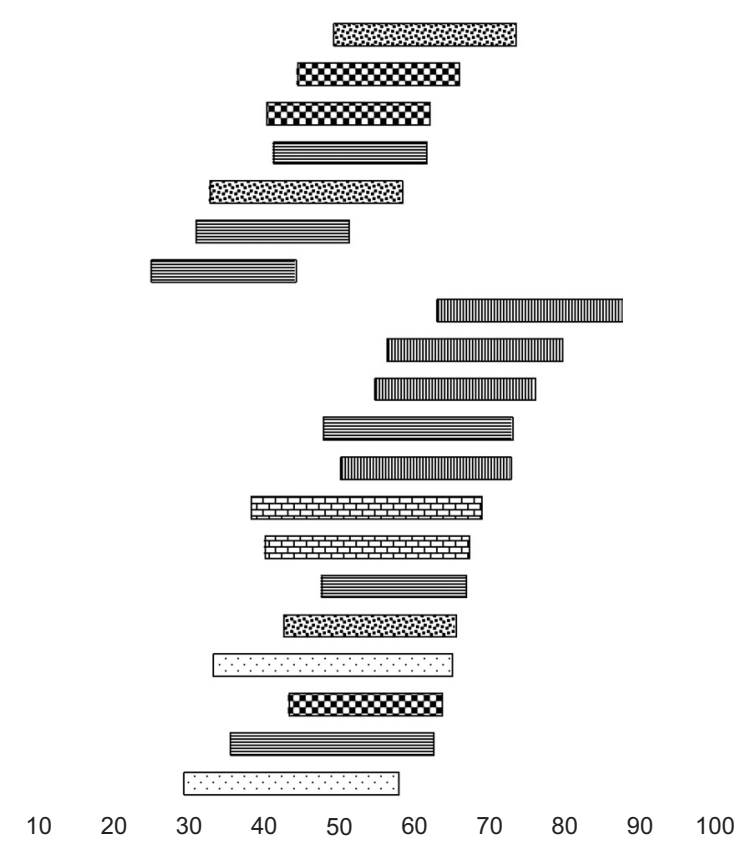

Fig. 5 Rank means for (a) public sector and (b) private sector non-public health specialists' perspectives (血, education; 留,

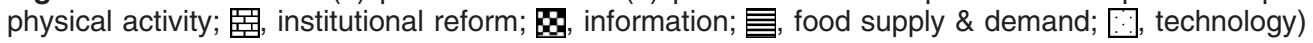

was only shown by representatives of the pharmaceutical industry, and a few senior food industry representatives.

I don't support such punitive measures. If a food product meets the compulsory health requirements, it should not be taxed further, this would be an unfair measure [there is no such thing as unhealthy food per se, the problem is overconsumption].

(PHS, Hungary)
Educational initiatives were considered to have the best potential performance according to the PHS, followed by the options concerning mandatory nutritional labelling, improving community sports facilities and controlling food and drink advertising.

There is evidence for physical activity, but it's whether improving facilities will automatically lead to take up of those facilities.

(PHS, UK) 
(a) 5. Mandatory nutritional information labelling (C) 4. Controlling sales of foods in public institutions (C) 2. Improve communal sports facilities (C)

3. Controls on food and drink advertising (C) 6. Subsidies on healthy foods $(C)$

7. Taxes on obesity-promoting foods (C) 1. Change planning and transport policies $(C)$ 8. Improve training for health professionals (D)

15. Food and health education (D)

10. Improved health education (D)

20. Physical activity monitoring devices (D)

14. Provide healthier catering menus (D)

18. New government body (D)

13. More obesity research (D)

11. Controls on food composition (D)

19. Control of marketing terms (D)

12. Incentives to improve food composition (D)

9. Common Agricultural Policy reform (D) (UNAPPRAISED) 16. Medication for weight control (D)

$$
\text { ff }
$$
(UNAPPRAISED) 17. Substitutes for fat and sugar (D)$$
\text { Change planning }
$$

3. Controls on food and 6. Subsidie

4. Controlling sales of foods in

(RULED OUT BY SOME \#1) 7. Taxes on obesity-

15. Food an

10. Improved

8. Improve training for hea

14. Provide health

18. New 16. Medication

13. More

11. Controls on

12. Incentives to improve

20. Physical activity
9. Common Agricult
17. Substitutes
19. Control of

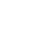


Figure 3 indicates the fractional contributions towards the overall evaluations provided by criteria of efficacy on the part of PHS in the top graph and NPHS in the lower graph. Figure 4 provides a similar representation with respect to criteria relating to the impact on public expenditure. An optimistic score to the right indicated low expected costs, while a pessimistic score to the left implies high costs. As regards efficacy criteria, the PHS considered that exercise and physical activity-oriented options are the most crucial aspect, followed by those aimed at improving health education among the population in general, as well as in the school curriculum. The NPHS were generally less optimistic about the likely efficacy of those types of measures. Nevertheless, for discretionary options they considered those related to education and controlling food consumption as most significant. Among the core options, both PHS and NPHS judged the option of improving community sports facilities as likely to be relatively effective.

The corresponding patterns in Fig. 4, relating to the economic impact on the public sector criterion, are markedly different. The PHS preferred informationrelated initiatives, among both core and discretionary options. They also favoured applying taxes to obesogenic products, in conjunction with educational initiatives, while also expecting a positive effect on reducing obesity. On the other hand, PHS judged the exercise and physical activity oriented to be particularly costly.

In the NPHS evaluations, controls of food and drink advertising, control on marketing terms and mandatory nutrition labelling were seen as relatively inexpensive, while changing planning and transport policies and reform of the Common Agricultural Policy were judged to be rather expensive.

\section{Public bealth specialists $v$. non-public bealth specialists from the public sector and the private sector}

A further analysis differentiated among NPHS interviewees between those in the public sector and those in the private sector. Marked similarities emerged between those in the public and private sectors in the mapping of the options for educational initiatives (Fig. 5). Compared with the findings shown in Fig. 1, a marginally greater agreement between the options that were more highly ranked by PHS and NPHS-PrS was evident (Fig. 5). This comparison reflects the more favourable attitude of the NPHS-PrS towards institutional reforms, which was, unsurprisingly, ranked higher than options oriented at modifying the supply and demand of foodstuffs. Another interesting finding is the relatively optimistic score assigned by NPHS-PrS to the use of synthetic substitutes for fats and sugars although, like the NPHS-PuS, this option was ranked among the lowest overall.

When comparing PHS with NPHS-PuS, both agreed that educational initiatives are the most critical, although
PHS tended to be more optimistic about their potential performance. On the other hand, the NPHS-PuS ranked informational initiatives in the second place, while the PHS awarded one of the lowest scores to the options of controlling marketing terms among this option cluster. Finally, resorting to technological innovations was one of the least valued options according to NPHS-PuS, with an even lower score than the fiscal measures of taxation on 'unhealthy' foods and subsidies on 'healthy' foods. However, the PHS indicated a potentially low performance for the core options related to taxes and changes in planning and transport policies, and for the discretionary options related to substitutes for fats and sugars and common agricultural policy reform.

\section{Public bealth specialists from Mediterranean and non-Mediterranean countries}

In a geographical comparison, stakeholders from both PHSM and the PHSNM agreed that educational measures are the primary options for tackling the issue of obesity in Europe (see Fig. 6), but none claimed that educational measures on their own would be sufficient. It is interesting to note that for PHSM, the technological innovations options were not seen as particularly significant, whereas PHSNM considered those options more optimistically. This latter group also assigned a relatively high rank to the use of medication to control body weight. Furthermore, the PHSM assigned a good potential performance for devices used to monitor physical activity, which was the option that the PHS scored most highly under the efficacy criterion.

A body of competent people should be set up. The body will select (can be on competition basis) healthy, good for health and slimming products.

(PHS, Poland)

\section{Discussion}

Our analysis shows that the perspective of PHS is widely shared by a broad range of other key European stakeholders. A consensus emerged that a package of public policies is required to deal with the current obesity epidemic. With educational aspects as a necessary but not sufficient component, stakeholders emphasised several other environmental level measures to improve citizens' lifestyles and society. However, when differing groups are analysed separately, several differences of opinion were evident, not only because of vested interests of the various sectors but also because of regional, political and governmental differences.

The findings concerning the choice of criteria selected by interviewees to evaluate policy options were consistent with those found in previous studies, confirming that decisions related to health intervention choices are complex and multifaceted ${ }^{(22,23)}$. Although greater 
agreement was reached on criteria such as efficacy than on criteria such as public expenditure costs, PHS and policy makers must take important judgements regarding the allocation of public funds, priority illnesses, target groups and interventions to be implemented. It may be for this reason that the PHS assigned greater weight than other stakeholders to the criteria related to economic costs to the public sector, although in overall rankings, when all criteria are weighted and integrated, the impact of the differences in selection criteria and their weightings is marginal.

The similarities and differences in perspectives found in the present study between various types of stakeholders provide important information for the design of national and European interventions. These interventions should be evaluated both as an integrated set and individually, given the possible interaction between them, their likely costs and/or effects ${ }^{(23)}$. On the other hand, an intervention strategy may be influenced not only by resistance from industry but also by the possible future political consequences of such a strategy outside the health sector ${ }^{(14,15,24)}$. Collective action within Europe may be hindered by a fragmented institutional architecture at many levels of governance ${ }^{(25)}$.

When developing strategies at different national and international levels, consideration should be given to the various ways in which particular policy measures may interact with international, regional and individual frameworks, social policies and national legislation, organisational and business practices, controls on regional planning and strategies, cultural and community practices, school and working life, family habits and choices, and individual actions $(3,6,26)$

There exists a broad consensus about the need to introduce educational measures for the population. Such measures are seen as a foundation upon which multifaceted public health and nutritional policies may be built. One key aim is to ensure that citizens are better informed about the relationship between food and health, energy intake and expenditure, diets that reduce the risk of suffering from chronic illnesses and healthy food options ${ }^{(27)}$. Although a number of partially successful experiences have been reported $^{(28)}$, policies based solely upon educational initiatives will not be sufficient to combat population obesity ${ }^{(2,29)}$. Although some dietary knowledge is necessary to persuade individuals to choose health-promoting behaviours ${ }^{(30,31)}$, that remains only one predisposing factor influencing the complex behaviour of eating ${ }^{(32)}$, alongside factors such as attitudes, risk perception and social norms ${ }^{(33)}$. Accurate nutritional knowledge may be particularly important when individuals are ready to make dietary changes ${ }^{(31)}$ and when combined with behavioural and motivational strategies ${ }^{(34)}$. Moreover, environmental and cultural factors will need to change if individual behaviour is to change. The consumption of food is both a biological and a cultural issue affected by individual preferences and influenced by social and economic factors ${ }^{(15,35)}$.

Finally, and taking into account the methodology used in the present study, caution should be exercised when interpreting the results; the final map of options corresponds to averages between the ranges of all participants, with variations in scoring under different criteria for each participant and between participants when the categories are combined. A loss of accuracy in the information is therefore unavoidable when aggregating and averaging. Additionally, the position of different stakeholders could have been influenced by their commercial interests and/or their professional expertise. A quantitative check indicated however that omitting potentially self-serving judgements changed the overall outcomes by no more than $\pm 1 \%{ }^{(36)}$.

To sum up and based on the different analyses that have been conducted, obesity can be seen as a consequence of economic development, which together with the current trends of a consumer society have triggered one of the main macroeconomic health problems that EU governments must face. As a consequence, isolated policies and individual actions are likely to only have a minimal effect and will not suffice to solve the problem.

The recommendations of PHS are widely shared by NPHS, which recognised the need to implement a package of measures in order to turn current trends in obesity around. For the PHS, the public policy framework should include educational initiatives and measures related to providing healthy catering services, improving community sports facilities, mandatory nutritional labelling, and controls on food and drink advertising, as the options with the best potential performance for tackling obesity.

\section{Acknowledgements}

Sources of funding: The project was financed by the European Union. This paper was supported by New and Emerging Science and Technology (NEST) research programme, financed by the 6th Framework Programme for research and technological development of the European Commission (Contract No. 508913).

Conflict of interest: To the best of our knowledge, there is no conflict of interest to declare.

Authorship responsibilities: All the authors fulfil the authorship criteria, making substantial contributions to the paper. The conception and design were by L.I.G.Z. and C.A.-D. taking advantage of a data bank with contribution of all the authors and other researches named in the acknowledgements. The analysis and interpretation of data were by L.I.G.Z., C.A.D. and V.C. initially, and was circulated to all the authors who contributed to its refinement, specially M.H., K.S., G.T., Z.H., E.M., T.L., S.S. and R.O. The drafting of the paper and revising several versions critically for its intellectual content were done by all of us and also all have read and approved the final version of the manuscript sent to Public Health Nutrition. 
Acknowledgements: The research team is greatly indebted to all European stakeholders who participated in the project and devoted their precious time to the project. The research team wishes to express their sincere thanks to the national PORGROW teams for sharing their cross-national PorGrow database, and our partners Patrik Borg from UKK Institute for Health Promotion Research (Finland) and Lucjan Szponar from National Food and Nutrition Institute (Poland). This paper will be used as part of L.I.G.'s PhD training programme and dissertation at the University of Alicante, Spain. The content of this publication is the sole responsibility of its authors and does not necessarily reflect the views or policies of the NEST research project or the European Commission.

\section{References}

1. World Health Organization (2006) Global Database on Body Mass Index. http://www.who.int/bmi/index.jsp (accesed April 2006).

2. International Obesity Task Force and the European Association for the Study of Obesity (2002) Obesity in Europe: A Case for Action. London: IOTF; available at http://www.iotf.org/ media/euobesity.pdf

3. Popkin BM \& Gordon-Larsen P (2004) The nutrition transition: worldwide obesity dynamics and their determinants. Int J Obes Relat Metab Disord 28, S2-S9.

4. World Health Organization (2003) Diet, Nutrition and the Prevention of Chronic Disease. Report of a Joint FAO of the United Nations/WHO Expert Consultation. WHO Technical Report Series no. 916. Geneva: WHO.

5. Orfanos P, Naska A, Trichopoulos D et al. (2007) Eating out of home and its correlates in 10 European countries. The European prospective Investigation into Cancer and Nutrition (EPIC) study. Public Health Nutr 10, 1515-1525.

6. Hill JO, Peters JC \& Wyatt HR (2007) The role of public policy in treating the epidemic of global obesity. Clin Pharmacol Ther 81, 772-775.

7. Nestle M (2006) Food marketing and childhood obesity - a matter of policy. New Engl J Med 354, 2527-2529.

8. Byrd-Bredbenner C \& Grasso D (2000) What is television trying to make children swallow? Content analysis of the nutrition information in prime time advertisements. $J$ Nutr Educ 32, 187-195.

9. Schwartz MB \& Brownell KD (2007) Actions necessary to prevent childhood obesity: creating the climate for change. J Law Med Ethics 35, 78-89.

10. Epstein R (2005) What (not) to do about obesity: a moderate Aristotelian answer. Georgetown Law J 93, 1361-1386.

11. Winson A (2004) Bringing political economy into the debate on the obesity epidemic. Agric Hum Values 21, 299-312.

12. Kim S \& Popkin BM (2006) Understanding the epidemiology of overweight and obesity. A real global public health concern. Int J Epidemiol 35, 60-67.

13. Sanz de Galdeano A (2005) The Obesity Epidemic in Europe. IZA Discussion Paper no. 1814. Bonn: Institute for the Study of Labor; available at http://ssrn.com/abstract $=840745$

14. Alderman J, Smith JA, Fried EJ \& Daynard RA (2007) Application of law to the chilhood obesity epidemic. J Law Med Ethics 35, 90-112.

15. Gostin LO (2007) Law as a tool to facilitate healthier lifestyles and prevent obesity. JAMA 297, 87-90.

16. Lachat C, Van Camp J, De Henauw S, Matthys C, Larondelle Y, Remaut-De Winter AM \& Kolsteren P (2005) A concise overview of national nutrition action plans in the European Union Member States. Public Health Nutr 8, 266-274.

17. Pasteur K (2001) Tools for Sustainable Livelihoods: Livelihoods Monitoring and Evaluation. Brighton: Institute for Development Studies.

18. Stirling A (2006) Analysis, participation and power: justification and closure in participatory multi-criteria appraisal. Land Use Policy 23, 95-107.

19. Stirling A (2005) Multi-criteria Mapping: A Detailed Analysis Manual, version 1.1, produced for the Porgrow Project, SPRU. http://www.sussex.ac.uk/spru/1-4-7-1-8-2-1.html

20. Stirling A, Lobstein T \& Millstone E (2007) Methodology for obtaining stakeholder assessments of obesity policy optons in the PorGrow project. Obes Rev 8, Suppl. 2, $17-27$.

21. Millstone E \& Lobstein T (2007) The PorGrow project: overall cross-national results, comparisons and implications. Obes Rev 8, Suppl. 2, 29-36.

22. Mills A, Bennett S, Bloom G, González-Block MA \& Pathmanathan I (2004) Strengthening Health Systems: The Role and Promise of Policy and Systems Research. Alliance for Health Policy and Systems Research. http:// www2.alliance-hpsr.org/jahia/Jahia/pid/184

23. Baltussen R \& Niessen L (2006) Priority setting of health interventions: the need for multi-criteria decision analysis. Cost Eff Resour Alloc 4, 14.

24. Kersh R \& Morone J (2002) The politics of obesity: seven steps to government action. Health Aff 21, 142-153.

25. Lang T \& Rayner G (2005) Obesity: a growing issue for European policy? J Eur Soc Policy 15, 301-327.

26. World Health Organization (2005) The Challenge of Obesity in the WHO European Region. Fact sheet EURO/13/05. Copenhagen: WHO Regional Office for Europe.

27. Comisión de las comunidades europeas. Libro verde (2005) Fomentar una alimentación sana y la actividad física: una dimensión europea para la prevención del exceso de peso, la obesidad y las enfermedades crónicas. http://ec.europa. eu/health/ph_determinants/life_style/nutrition/documents/ nutrition_gp_es.pdf

28. Kafatos A, Manios Y \& Moschandreas J (2005) Health and nutrition education in primary schools of Crete: follow-up changes in body mass index and overweight status. Eur J Clin Nutr 59, 1090-1092.

29. Bautista-Castaño I, Doreste J \& Serra-Majem LL (2004) Effectiveness of interventions in the prevention of childhood obesity. Eur J Epidemiol 19, 617-622.

30. Parmenter K, Waller J \& Wardle J (2000) Demographic variation in nutrition knowledge in England. Health Educ Res 15, 163-174

31. Holdsworth M, Haslam C \& Raymond NT (2000) Does the Heartbeat Award Scheme change employees' dietary attitudes and knowledge? Appetite 35, 179-188.

32. Green LW \& Kreuter MW (1999) Health Promotion Planning: An Educational and Ecological Approach. California: Mayfield Publishing.

33. McCaffery K, Wardle J \& Waller J (2003) Knowledge, attitudes and behavioural intentions in relation to early detection of colorectal cancer in the United Kingdom. Prev Med 36, 525-535.

34. Anderson AS, Cox DN, McKellar S, Reynolds J, Lean ME \& Mela DJ (1998) Take 5, a nutrition education intervention to increase fruit and vegetable intakes: impact on attitudes towards dietary change. Br J Nutr 80, 133-140.

35. Robertson A, Tirado C, Lobstein T et al. (2004) Food and Health in Europe: A New Basis for Action. WHO Regional Publications, European Series no. 96. Copenhagen: WHO.

36. Lobstein $\mathrm{T}$ \& Millstone E (2006) Policy Options for Responding to Obesity: Evaluating the Options, p. 19. Brighton: University of Sussex; available at http://www. sussex.ac.uk/spru/documents/porgrow_complete.pdf 